\title{
How do government agencies review and approve text content for publication on their Web sites? A framework to compare Web content management practices
}

\author{
Kristin R. Eschenfelder \\ School of Library and Information Studies, University of Wisconsin-Madison, 4228 H.C. White Hall, \\ 600 North Park Street, Madison, WI 53706-2105, USA
}

Available online 21 July 2004

\begin{abstract}
This article describes a multicase field study of four public-facing Midwestern state agencies and how they organized the work of reviewing and approving textual content for publication on Internet Web sites. Drawing on field data and concepts from institutional theory, contingency theory, and organizational design, the paper generates a framework to document systematically the processes and practices involved in the review and approval of textual Web content. The framework is then used to compare textual content management practices across the four case sites and to begin to investigate the effects of variation in content management practices on characteristics of the available textual content. The article suggests how the framework could be used in future research to investigate how content practices affect content characteristics such as quality, quantity, and cost and to investigate how and why content management practices change over time.
\end{abstract}

(C) 2004 Published by Elsevier Inc.

\section{Introduction}

Textual content on government Web sites is an important source of information. Citizens increasingly use information on government Web sites to research issues, understand government programs, and obtain benefits (Larsen \& Rainie, 2002). Past scholarship has argued that the dissemination of government information educates the citizenry, increases

*E-mail address: eschenfelder@wisc.edu. 
government transparency, and aids economic development (Hernon \& Relyea, 1995). Much e-government research has focused on online applications, such as e-voting or service registration systems (Cresswell \& Pardo, 2001; Moon, 2003). While important, these studies tend to overlook text-based or "static" content such as program descriptions, frequently asked questions, or instructions (typified as Stage 1 or Stage 2 e-government activities; Layne \& Lee, 2001). Yet, some studies suggest that citizen demand for basic textual information is higher than their demand for interactive applications (Gartner Research, 2002).

While citizens' growing use of Web-based government information requires that agencies ensure both the timeliness and the quality of this textual information, there is little knowledge of how agencies manage the work required to create and maintain quality textual content. The processes and practices that drive the creation and approval of text content for publication are currently hidden behind the public Internet Web site. A number of studies rate the quality of government Web sites and their content (Barnes \& Vidgen, 2003; Demchak, Friis, \& La Porte, 2000; Ho, 2002; West, 2002), but less work has examined how agency staff create and maintain Web site content.

One explanation for this research gap is the lack of a framework for studying Web content management practices (WCM practices). Managing content is a complex endeavor involving the coordination of different tasks and actors through formalized policies, informal practices, and shared understandings. Describing this activity without any guidance as to what factors may be important is a daunting endeavor. What is needed is a framework, or a set of predefined factors, through which to describe WCM practices. As government agency Web managers seek to reduce operating costs, increase citizen satisfaction, and guarantee the quality of textual content on their Web sites, it is important to have a tool to compare and evaluate WCM practices over time or across organizations. It is also important to determine how different WCM practices affect the characteristics of the content published on the Web.

This article describes an exploratory study to develop a WCM framework. The descriptive, multicase field study examined how four agencies in one Midwestern state organized the work required to review and approve text-based Web content prior to publication. The goal of the study was to develop a grounded framework, based on concepts from the institutional, contingency theory, and organizational design literatures, through which to measure and compare WCM practices across different organizations. As described in Fig. 1, the development of a framework is a necessary antecedent to examining the effect of WCM on desired outcomes. One cannot study effects of variation in WCM practices without a means of systematically describing WCM practices across organizations and across time.

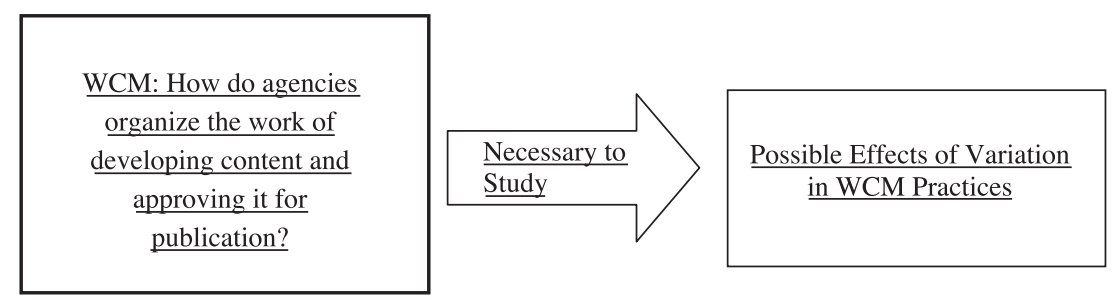

Fig. 1. Relationship of WCM framework to possible effects of variation in WCM practices. 


\section{Management of government Web sites}

Managing Web content is neither cheap nor easy. Studies suggest that government agencies underestimate the work required to identify and convert content to Web formats and keep content up-to-date (Dawes, Pardo, \& DiCaterino, 1999; Jupiter Research, 2003). WCM-related labor is typically an add-on to previously existing responsibilities and may be seen as lower priority work during periods of budget or time constraints (Coursey \& Killingsworth, 2000). Content may be developed without planning for long-term maintenance or funding (Christensen \& Hughes, 2000). Further, agency staff often have few resources to maintain existing content (Fountain, 2001). At the same time, funding for content is dependent on the interests of top agency management, which may change with electoral cycles (Coursey \& Killingsworth, 2000).

Agency Web sites are composed of thousands of digital files managed by subject experts and Web staff in programs located within agency programs. Given that Web sites change over time as content, business goals, and customer expectations change, managing content is an ongoing expense for agencies. Some changes are simple changes, such as changing a phone number; while other changes are more significant changes, such rewriting a program description necessitated by a change in law. Sometimes changes in policy or the development of new initiatives require creation of completely new Web pages within the larger Web site. Other changes involve sensitive content that may attract public attention or generate criticism of the agency (Eschenfelder, 2004). Many Web sites never experience a lower-cost "maintenance" phase seen in traditional systems development characterized by low or no change (Orlikowski, 2000; Swanson, 1976; Truex, Baskerville, \& Klein, 1999).

WCM seeks to reduce the costs of maintaining content, increase oversight of content publication and improve the quality of content (Boiko, 2001; Hackos, 2001; Nakano, 2002). A good deal of WCM practice literature conceptualizes management of content in terms of a "virtual assembly line" of processes, which should be optimized in order to maximize output (in terms of time to publish or amount of new content) while reducing overall operating costs (Nakano, 2002). In this view, content is passed from employee to employee, with each employee applying their assigned skill (e.g., editing, approval, and uploading). Typical process phases include planning, creation, editing, approval, and deployment.

\section{Organizational structure and design}

While WCM is a new arena of inquiry, other research has sought to understand how organizations manage work practices and arrange relationships between staff members. For example, research using contingency theories often seeks to understand how organizations can manipulate coordination and control mechanisms to try to achieve desired outputs existing contingencies (Donaldson, 1995). Institutional theories examine the creation of structures within organizations such as formalized regulations and 
expected ways of doing things (Oliver, 1991; Scott, 2001; Zucker, 1987). Organizational design research examines how organizations organize themselves to manage uncertainties and achieve goals (Galbraith, 1974, 1977; Mintzberg, 1979). The WCM framework draws on concepts from these literatures to describe how the case sites organized the work of reviewing and approving Web content.

The framework draws on several constructs from the literature. The construct "organizational complexity" describes how an organization arranges its members for management purposes. Measures include the number of divisions or specializations in an organization (Rainey, 2003), the logical arrangement of those groups (e.g., by expertise, process, time, or matrix) (Mintzberg, 1979), and the number of hierarchical levels in the organization (Rainey, 2003). "Concentration of authority" is the degree to which power and authority are centralized within an organization (Pugh, Hickson, Hinings, \& Turner, 1969; Rainey, 2003). It has been measured in terms of span of control, or the average number of employees under one supervisor. Formalization focuses on the degree to which rules, policies, and procedures are formalized (i.e., established in written rules and regulations) (Pugh et al., 1969; Zucker, 1987) and the degree to which practice is dynamic or regular (Pugh et al., 1969).

Based on this literature, this article defines WCM practice in terms of the structural elements that agencies create to manage the work of reviewing and approving content for publication on agency Web sites. WCM structural elements include all arrangements and relationships governing the coordination and control of WCM work (Perrow, 1967).

\section{Study design and methods}

Because the goal of the research was to build a framework to study WCM, the study used an exploratory multiple case study design with predominately qualitative data collection methods. Qualitative studies are recommended when investigating phenomena in which dependent and independent variables are not well understood (Creswell, 1994) and when there is a tight interconnection between the phenomena of interest and their organizational contexts (Yin, 2003). The exploratory case approach is used to develop theory for use in future studies (Eisenhardt, 1989). The multiple case design allowed replication of results, increasing their validity (Yin, 2003).

Sampling at the organizational level was based on the size of the agency, the public orientation of the agency, and the size of the Web sites. This article refers to the agencies as the Departments of Parks and Environmental Protection (PEP), Welfare, Labor, and Transportation. The agencies were all large, with over 2,000 permanent employees and five or more divisions. In each agency, a significant portion of operations involved contact or communications with the public. Further, PEP, Welfare, and Labor had large Web sites (i.e., over 10,000 pages). Transportation was selected to produce contrasting results and to begin to test the relationship between framework elements and one particular outcome - the number of PDF and HTML files contained within the agency Web site. Although Transportation was a large agency with many public-facing programs, 
it maintained a much smaller Web site (approximately 2000 pages), and it was known for having more formal and extensive content management practices.

Within each agency, interviews included Web masters, content planners, content creators, and content approvers. All participants worked with content for public-facing Internet Web sites. Each case included data from at least two different programs within each agency; but analysis for this article aggregates the data, and the organization is the unit of analysis.

\subsection{Data collection and analysis}

Results stem primarily from semistructured interviews with thirty state agency Web staffers. Interviews took place from May through September of 2002 with scattered followup interviews through Fall 2003. Some employees were interviewed multiple times, and some additional background interviews were conducted with non-Web staff. Interview transcripts were shared with the participants in order to increase their accuracy and validity.

A second source of data consisted of documents from each agency describing WCM policies or procedures, WCM-related forms, agency publications, and background information on each agency. Background data were drawn from agency Web sites, the state government almanac, and from agency Intranets.

Data about Web site size and composition came from searches on the state Ultraseek search engine. The search engine indexed the Web sites of the four participating agencies at least every two weeks. It indexed all pages under the root URLs identified by agency staff as suitable for inclusion in the index (e.g., www.agencyname.state.gov/). Searches used HTML and PDF file type delimiters to generate a count of the total HTML and PDF file page indexed by the state search engine. ${ }^{1}$

A theory elaboration analysis approach was used to construct the WCM framework. In this approach, the researcher compares theoretical constructs from the literature with grounded field data to elaborate the constructs or generate new constructs (Strauss \& Corbin, 1998; Vaughan, 1992). Analysis involved comparing the constructs from the literature with WCM practices at each case site and adapting the constructs to describe the observed practices better.

Following the model of the multiple case study design, analysis first produced a separate report for each site, comparing the practices of the participating programs within each agency (Eisenhardt, 1989). Then, using the constant comparative method, the data from each case were compared with the existing literature and with data from the other cases. A draft framework was generated after the analysis of each case. The draft framework was then compared with the data from next case to see to what extent the draft framework could describe the work practices at that case site. Adjustments and additions to the framework were made after each case, culminating in a final version after the last case site. Analysis also employed cross-case comparison

\footnotetext{
${ }^{1}$ See Section 7 for a discussion of limitations of this measurement of Web site size.
} 
tables to both organize data from different sources (i.e., interview vs. documents) and to compare data across case sites (Miles \& Huberman, 1994). The Atlas-TI software was used to organize and code interview data and manage data analysis memos.

\section{Findings}

This section is divided into two parts. Following the multiple case site research design tradition, the first part presents summaries of the data from each case site, providing a rich description of how each agency organized the work of reviewing and approving content for publication. The second part presents the WCM framework and uses it to point to similarities and differences in WCM practices across the case sites.

\subsection{Case site summaries}

\subsubsection{Parks and Environmental Protection}

The mission of PEP included protection of natural resources, licensing and regulation of recreational activities, planning and management of public land, and regulation of businesses and utilities. The agency included seven divisions and twenty-three bureaus. Staff from six divisions participated in the study.

Content approval in PEP involved three actor groups: "publishers," "Internet Managers" (IM), and an agency-level Web site review board. (Note: Section 5 uses the position names actually employed by agency staff.) Ten total Web staffers participated, including representatives of each of the actor groups.

Within PEP, publishers created Web content, but IM approved content prior to publication. Staff members interested in creating a Web page or making changes to existing Web pages would consult the IM who would plan the project and either act as publisher or assign a publisher to the project. The IM ensured that content met both agency policies and bureau Web policies and coordinated Web activity of the publishers in their bureau. Although agency policy required IM approval for content publication, both IM and publishers had rights to publish content to Internet servers. Typically, each bureau had one IM. At the time of the study, PEP had a total of thirty-seven IM and over 100 publishers.

Agency policies did not spell out how local review should occur, and the data show that local processes varied across different programs. In general, the local approval process was highly dynamic with IM making decisions about which content required further approval and who should approve it. For example, some IM required that publishers send them all their new content and any content changes, except for very minor changes. In other programs, publishers were more autonomous, publishing their own content and only interacting with the IM if they needed agency-level approval.

IM also varied in terms of the formality of local review processes. Some IM required that all requests for content changes be copied to the submitting staff member's supervisor, but other IM only required proof of a supervisor's approval if the changes seemed sensitive. 
PEP policy required more formal review for new content and for significant changes to existing Web pages (PEP defined a significant change as a change that affected over 50 percent of the site's content or required a new subdirectory). Policy required that IM complete a publications request form for these content types (complete with a division manager's signature) and forward the form to an agency-level review board for approval. Minor changes to content were only reviewed locally.

\subsubsection{Welfare agency}

The Welfare Agency (Welfare) administered health programs and institutions, regulated care providers, supervised public and nonprofit health and welfare agencies, and provided public health, mental health, substance abuse, long-term care, disability assistance, medical assistance, and children's aid services. The agency had six divisions and twenty-seven bureaus.

Content review at Welfare involved both "authors" and "divisional approvers" (DA). Participants included four authors, three DA, and the agency Web masters. At Welfare, authors worked with subject area experts to develop content from scratch or from existing documents, and they served as front-line reviewers, ensuring that new content met agency style and accessibility guidelines.

Agency policies did not stipulate how authors should obtain local approval within their programs. Similar to PEP, the nature of the local approval processes varied in terms of what types of content required approval and who gave approval. The degree to which authors obtained local approval for changes to existing content varied based on the relationship between the author and the local managers. Typically, authors and managers sought to streamline the approval process by granting authors the authority to make smaller changes without manager's involvement.

While the local approval process was more informal and flexible, agency policy required that authors pass all locally approved content to DA who further reviewed the content. Only DA had rights to publish content to the Internet server, so all content (i.e., even minor changes) had to pass through the DA prior to publication. While the DA reviewed all content, they reported giving more extensive review to new content and significantly changed content and less extensive review to small changes. Typically, the review and approval processes ended with the DA. Only sensitive content was forwarded to the secretary's office for agency-level review.

\subsubsection{Labor agency}

Labor had responsibility for the state's employment and training services, employment discrimination, the state's "Welfare to Work" program, unemployment insurance, child support, workers' compensation, work apprenticeship programs, and employment-related services for people with disabilities. Labor was composed of six divisions and six offices.

The content review process in Labor involved three actors: "authors," "publishers," and "Web coordinators" (WC). A total of seven Web staffers participated: four who acted as authors and publishers, two who acted as WC, and the agency Web master. Authors created content for the Web site and then forwarded it to publishers, who could 
publish it to the Internet server. Publishers did not approve content. Typically, a bureau had multiple authors who sent content to publishers at the bureau or division level.

The approval processes within Labor were largely limited to local-level approval, and the exact nature of the approval procedures varied by division, and in some cases, by bureau. In all programs but one, local managers approved new content prior to publication. In most cases, the approval was informal-most programs did not have official forms for approval, in many cases approval was taken for granted because the manager was involved in the creation of the content.

In the case of significant changes to existing content, the degree of oversight varied depending on the relationship between the author and her manager. In some cases, authors always forwarded changed material for approval. One program described how they had an "unwritten rule" that staff would talk over any new content or significant changes with their managers. In the case of minor changes to existing content, authors reported not seeking local approval and just sending the content to publishers for posting.

Each division also had a WC who enforced standards and coordinated Web activities within the division. In most cases however, the WC did not approve content prior to publication. But in one program area, the WC acted as a final stage content approver. This division had a more formalized review process involving a publication request form that required information about responsible parties, who had approved the content, and the expiration or review date for the content.

In all cases, authors and publishers explained how they would forward sensitive content to the agency public information officer for further review. Most staff also spoke of forwarding potentially sensitive content to upper-level managers for advice or to alert them to its imminent publication.

\subsubsection{Transportation agency}

Transportation was responsible for planning, promoting, and protecting highways, railroads, waterways, mass transit, and aeronautics within the state. Transportation was composed of six divisions and three offices. Content review within Transportation involved three actors: "divisional Web administrators" (DWA), the agency communications office (Communications), and the agency secretary's office. Study participants included DWA from three divisions with high levels of public interaction, staff from Communications, and Web masters from the agency IT bureau.

The content approval process in Transportation was formalized in an agency policy requiring all new content, and significant changes to existing content (Transportation also defined significant as involving more than 50 percent of the content on a Web page), to move through a regularized process involving the DWA, Communications, and the agency secretary's office. The process for updating existing content was more informal and dynamic - parts of the process were not documented and changed depending on the type of content or people involved.

Program staff desiring to put new content on the Web would first seek local approval from their manager and then would approach their DWA for assistance. The DWA would review the content, making sure that it fit with divisional goals and complied with 
agency policies. DWA did not use forms to track managerial approvals. At the time of the study, the DWA also converted the content to HTML. DWA had server rights to publish content and would publish all small changes without further approvals unless the change seemed potentially sensitive.

After obtaining the correct local signatures on an agency "publications request form," the DWA would clip a paper copy of the Web site to the form and route it through a three stage agency-level approval process. This process involved first the Communications staff assigned to the program, then the Communications chief, and then staff within the secretary's office. Transportation had the most required levels of approval of all the case sites.

As noted above, many changes to existing content were handled by the DWA without further approvals. The participating DWA reported not sending most significant changes through the official process, but instead informally alerting Communications to the change. DWA reported always alerting both divisional mangers and Communications to all sensitive content.

\subsection{Organizational comparisons via framework}

This section of the findings present the WCM framework. The framework outlines a set of common factors, or points of reference, to compare WCM practices across agencies. For convenience purposes, the article presents the framework in three sections: (a) agency and Web site characteristics, (b) WCM staff characteristics, and (c) WCM approval process characteristics. The article employs the framework to point to important similarities and differences across the case sites.

\subsubsection{Agency and Web site characteristics}

The first element of WCM practice to consider is the size of the agency and the size and composition of its Web site. As indicated by Table 1, the four agencies differed in number of employees and Web site size but were similar in terms of organizational structure, with each agency split into multiple divisions further subdivided into bureaus and then into programs.

Welfare, the largest agency, also had the largest Web site; but Labor, the smallest agency, did not have the smallest Web site. Combining PDF and HTML pages, both PEP and Welfare have significantly more Web content than Labor or Transportation. Transportation and Welfare used

Table 1

Agency and Web site characteristics

\begin{tabular}{lllll}
\hline & PEP & Welfare & Labor & Transportation \\
\hline $\begin{array}{l}2002-2003 \text { staff size } \\
\quad \text { rounded to the nearest hundred) }\end{array}$ & 2900 & 6000 & 2300 & 3500 \\
$\begin{array}{l}2002-2003 \text { agency budget (rounded } \\
\text { to the nearest million) }\end{array}$ & 9.5 million & 10.5 billion & 2 billion & 4 billion \\
$\begin{array}{l}\text { Approximate Web site size } \\
\quad \text { (HTML and PDF combined) }\end{array}$ & 26,844 & 21,830 & 9813 & 4771 \\
$\begin{array}{l}\text { Ratio of HTML to } \\
\text { PDF pages }\end{array}$ & 4 & 1.1 & 2.6 & 1 \\
\hline
\end{tabular}


more PDF files as an overall percentage of their Web content, and PEP created more HTML pages than any other case site. Section 6 considers the implications of these findings.

\subsubsection{WCM staff characteristics}

The second element of WCM practice to consider includes characteristics of the Web staff that do content-related work. In each of the four agencies, staff located in programs did most content work; but these staff typically held other primary program-oriented job responsibilities. Excluding the participants who were Web masters, only four out of the remaining twenty-four participants worked full time on Web content - and many of these individuals also had responsibility for paper publications.

This section uses the term "Web author" to refer to a staff member who creates Web pages. It uses the term "approver" to refer to a staff member with approval authority, and it uses the term "publisher" to refer to a staff member with server rights to publish content. The term "Web staff" refers to all three positions-or any program staff member who did Web-related work (authoring, approving, or publishing). As noted in Table 2, the number of Web staff varied across agencies. Dividing total numbers of staff by the number of Web authors, PEP had approximately twenty-three staff members per author, Welfare had thirty staff per author, and Labor had nine staff per author. In contrast, at Transportation, each Web author served an average of 109 staff members.

The percentage of work time Web staff could devote to content varied by what other job responsibilities the individual staffers held and how their supervisors directed them to allocate their work time. At PEP, Web authors estimated they spent between 5 and 50 percent of their work time on content. At Welfare, most authors spent less than 5 percent of their time on Web content. Labor authors estimated they spent less than 30 percent of their work time on Web content. Transportation authors spent between 40 and 50 percent of their work time for Web content.

Within agencies, the span of service and percentage of time devoted to content varied a great deal between programs. Programs with more resources tended to have more Web

Table 2

WCM staff characteristics

\begin{tabular}{|c|c|c|c|c|}
\hline Organizational $\mathrm{CM}$ variables & PEP & Welfare & Labor & Transportation \\
\hline Number of authors & 127 & 202 & 250 & 32 \\
\hline $\begin{array}{l}\text { Span of service: ratio of total } \\
\text { staff }^{a} \text { to Web authors }\end{array}$ & $\begin{array}{l}28 \text { staff } \\
\text { per author }\end{array}$ & $\begin{array}{l}33.5 \text { staff } \\
\text { per author }\end{array}$ & $\begin{array}{l}9.5 \text { staff } \\
\text { per author }\end{array}$ & $\begin{array}{l}129 \text { staff } \\
\text { per author }\end{array}$ \\
\hline $\begin{array}{l}\text { Percent of Web staff time } \\
\text { devoted to WCM }\end{array}$ & $\begin{array}{l}\text { Varies by program, } \\
\text { generally low }\end{array}$ & $\begin{array}{l}\text { Varies by program, } \\
\text { generally low }\end{array}$ & $\begin{array}{l}\text { Varies by program, } \\
\text { generally low }\end{array}$ & $\begin{array}{l}\text { Moderate } \\
\text { percentage of } \\
\text { time }\end{array}$ \\
\hline $\begin{array}{l}\text { Publisher span of service: ratio } \\
\text { of total staff to Web publishers }\end{array}$ & 17 & 187.5 & 46 & 205 \\
\hline
\end{tabular}

"All staff numbers in this article refer to "FTE" staff or full-time equivalent positions. These positions are career civil service and qualify for full state benefits. "LTE" or limited term employment positions are contract positions that do not qualify for benefits and are not included in staff numbers. 
authors and authors more fully devoted to Web content, while other programs had few authors or authors that spent only a small percentage of their work time on Web content.

The agencies also varied in terms of the number of publishers on hand to publish content. PEP had a large number of publishers, Labor had fewer, but Welfare and Transportation had the fewest.

The formality of Web work also varied between programs within the agencies. In some programs in PEP, Welfare, and Labor, content responsibilities were not formally included on all authors, publishers, and approvers' job descriptions. But all the participants at Transportation had Web duties officially included in their job description.

\subsubsection{WCM approval process characteristics}

A third element of WCM practice is how the agency has arranged the work of approving and publishing content. For example, agencies must decide what content requires approval, what constitutes an approval, and who should approve content. Agencies must also decide who should have the power to actually publish content to a live Internet site. For convenience purposes, the article presents this material in four subsections: levels of approval, concentration of approval and publication authority, formality of approval, and WCM tools.

5.2.3.1. Levels of approval. Participants explained that content approval processes varied in terms of the degree of change and the degree to which the content was sensitive. At each agency, small changes (e.g., changes to names, addresses, phone numbers, and dates) could be published with local review or no review. Significant changes required higher levels of review; but what counted as a significant change, and the nature and level of review it required, varied by agency and by program area within agencies. Each agency required that completely new Web pages receive more formal and higher level review. As indicated in Table 3, all agencies but Labor required at least three levels of review for new Web pages. Labor's review practices varied by division, but most only required two levels of review unless the content was sensitive.

Generally, agency staff had discretion as to whether a change counted as a significant change. They talked about using "best professional judgment" to determine whether a change was significant enough to require further review. Some participants argued that any content that fit within the framework or mission of the existing site did not count as a significant change-regardless of the actual amount of content. Participants also described strategies to minimize the appearance of change; for instance, staggering changes to minimize the relative degree of change (Eschenfelder, 2003).

Each agency had formal or informal procedures for treatment of sensitive content that might attract media attention or negative publicity. At each agency, staff reported forwarding sensitive content to the agency secretary's office for review and approval. At Labor and Welfare, authors or publishers had discretion in terms of what content they thought should receive secretary's office review. But at Transportation and PEP, all new content received full agency-level approval and thus received high-level review. 
Table 3

WCM approval process characteristics

\begin{tabular}{|c|c|c|c|c|}
\hline $\begin{array}{l}\text { WCM approval } \\
\text { element }\end{array}$ & PEP & Welfare & Labor & Transportation \\
\hline $\begin{array}{l}\text { Level of approval } \\
\text { for a minor } \\
\text { change }\end{array}$ & None & None & None & None \\
\hline $\begin{array}{l}\text { Level of approval } \\
\text { for a major } \\
\text { change }\end{array}$ & $\begin{array}{l}\text { Agency } \\
\text { review board }\end{array}$ & DA & $\begin{array}{l}\text { Bureau director } \\
\text { or divisional } \\
\text { administrator }\end{array}$ & $\begin{array}{l}\text { Communications } \\
\text { office or } \\
\text { secretary's office }\end{array}$ \\
\hline $\begin{array}{l}\text { Minimum number } \\
\text { of approvers } \\
\text { for new } \\
\text { Web page }\end{array}$ & $\begin{array}{l}\text { 3: Program/bureau } \\
\text { director, } \\
\text { IM, agency } \\
\text { review board }\end{array}$ & $\begin{array}{l}\text { 3: Program or } \\
\text { bureau director, } \\
\text { author, DA }\end{array}$ & $\begin{array}{l}\text { 2: Author, bureau } \\
\text { chief, or division } \\
\text { administrator }\end{array}$ & $\begin{array}{l}\text { 3: DWA, public } \\
\text { information office, } \\
\text { secretary's office }\end{array}$ \\
\hline $\begin{array}{l}\text { Formality of } \\
\text { review } \\
\text { process }\end{array}$ & $\begin{array}{l}\text { Formal at agency } \\
\text { or divisional levels, } \\
\text { informal at bureau } \\
\text { and program levels }\end{array}$ & $\begin{array}{l}\text { Formal at agency } \\
\text { or divisional levels, } \\
\text { informal at bureau } \\
\text { and program levels }\end{array}$ & $\begin{array}{l}\text { Formal at agency } \\
\text { or divisional levels, } \\
\text { informal at bureau } \\
\text { and program levels }\end{array}$ & $\begin{array}{l}\text { Formal at agency } \\
\text { or divisional levels, } \\
\text { informal at bureau } \\
\text { and program levels }\end{array}$ \\
\hline Tools employed & $\begin{array}{l}\text { Web authoring tool. } \\
\text { Form required for } \\
\text { higher level } \\
\text { approval. E-mail. }\end{array}$ & $\begin{array}{l}\text { Web authoring tool. } \\
\text { E-mail. }\end{array}$ & $\begin{array}{l}\text { Web authoring tool. } \\
\text { E-mail. }\end{array}$ & $\begin{array}{l}\text { Web authoring tool. } \\
\text { Form required for } \\
\text { higher level } \\
\text { approval. E-mail. }\end{array}$ \\
\hline
\end{tabular}

5.2.3.2. Concentration of approval and publication authority. The agencies varied in the degree to which their processes centralized publication and approval authority. Publication involved moving files from a test server to an Internet server. Approval involved extensive review of content to determine factual correctness, compliance with agency standards, the degree to which it supported division or agency priorities, and likelihood of attracting negative public attention (therefore requiring even higher level review). Welfare and Transportation explicitly linked publication and approval responsibilities by assigning both to a divisional-level approver. The other agencies separated publication and approval. In these cases, either publishers did not review content (Labor), or most authors had rights to publish (PEP and Transportation). In these agencies, staff could conceivably publish without receiving approvals, and the process relied on an honor system backed up by threats of removal of publication rights.

5.2.3.3. Formality of approval. The degree of formality of review and approval processes varied both by agency and by level of approval. In general, processes were more formal at the levels of division and above and more informal at the program and bureau-levels. PEP, Welfare, Labor, and Transportation had written procedures describing divisional- and agency-level processes. But most program or bureaus did not have formal plans describing local-level approval processes. Interviews suggested that local approval processes were more informal and flexible than divisional- or agency-level review processes.

Local approvals were typically done via e-mail or verbally: only one program (in Labor) used a form to track local approvals. The nature of local approval varied depending on the 
size of the bureaus, the nature of the content, and the relationships of the staff involved. Web staff used their best professional judgment to decide which content needed local approval and who should approve it. Local approval processes were dependent on trust and shared understanding between local management and Web staff as to what types of content managers really needed to see and what could be published without further review. In the case of small or regular changes, Web staff often published content without any approvals.

5.2.3.4. WCM tools used. At the time of the study, none of the case agencies employed a commercial software-based content management system. However, Web staff in each agency used Web authoring tools such as FrontPage or Dreamweaver; and these software packages included a number of content management tools including authoring features, file versioning, file transfer tools, and file management systems.

Each agency also employed existing software tools such as electronic mail and file servers to help manage the review and approval of content. Additionally, PEP and Transportation required the use of paper forms for high-level approval of new and significantly changed content. Welfare and Labor relied predominately on e-mail or faceto-face conversation to convey approvals for content.

But the lack of paper forms requirements did not mean that paper was not involved in the review and approval process. Results show that many authors in Welfare, which had a more extensive review process, printed off a paper copies of documents and submitted them for approval when the document represented new or significantly changed content. Transportation required that authors route paper copies during upper-level review processes. Many authors believed that providing a reviewer with a paper copy of documents expedited the review process by making it easier for the reviewer to indicate desired changes; otherwise, reviewers might have to write long and confusing e-mail messages referring to portions of text in an attached document. Many authors also preferred to hand deliver the content to the reviewer so that they could discuss the document, and some reviewers preferred to discuss requested changes face-to-face with authors so as to avoid misunderstandings or hurt feelings (Eschenfelder, 2003).

\section{Discussion}

The WCM framework is a work in progress and further research is expected to add and refine elements. The framework facilitates systematic description of WCM practices and variations in WCM practices across different organizations and across time. This contribution also lays the groundwork for research to begin to identify the effects of variation in WCM practices. As noted in Fig. 2, one could employ the framework to study how variations in WCM practice affect the amount of content that government agencies produce. Or one could examine the effect of WCM practices on characteristics of content - such as treatment of sensitive or highly political issues in content. Further, variations in WCM may affect costs associated with managing content. This section briefly considers each of these future areas of research. 


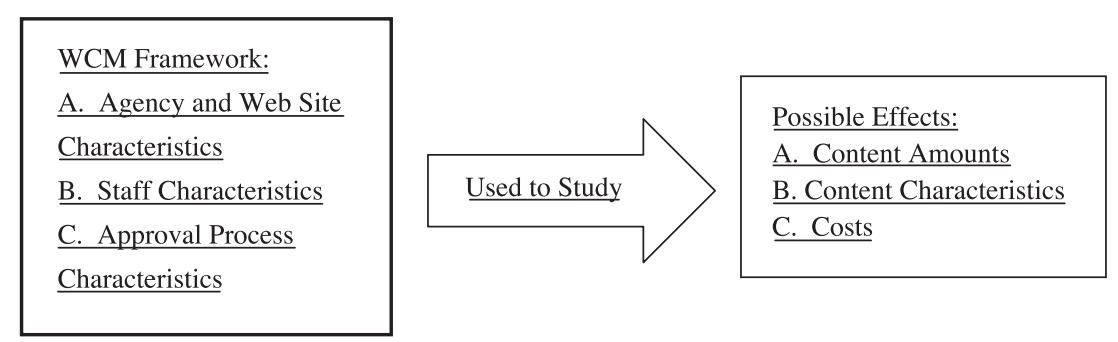

Fig. 2. WCM framework and potential effects of variation in WCM.

\subsection{How do variations in WCM effect the amount of content available to the public?}

One important question is to what degree does variation in WCM practice affect the amount of government information available to the public? Public managers are under pressure to reduce costs while maintaining or improving customer service. Textual Web site content is an important tool for fulfilling the customer service mission of government agencies (Eschenfelder, 2004; Sprehe, 1999); and it is important to understand how variations in WCM practices might affect the degree to which an agency can serve its public by providing useful information.

The study design and small sample size limit the degree to which the data can show relationship between WCM framework characteristics and Web site size. For example, data show that the four case agencies varied in terms of how much content they maintained on their Web sites. Results show that the agency with the smallest Web site (Transportation) had the fewest Web staff, but those staffers spent a greater percentage of their time on content work. The data cannot say why the other agencies had more content than Transportation. It may be that Transportation had less information to make available. Alternatively, the agency may have made a strategic decision to keep the amount of content on the site small to reduce management burdens.

Further, it is not clear from the results how variations in approval processes affect the amount of content available. Transportation, which had the smallest site, had the most extensive approval process. But Welfare and PEP, which had relatively extensive review processes, had very large Web sites. While common sense suggests that a burdensome review process could discourage content production, the results cannot say to what extent site size and approval process are related. Agencies could make better decisions about how to mange their content if managers had a clear understanding of if, or how, approval affected the amount of content produced for a Web site. Additional research is planned to test better the relationship between WCM framework elements and the amount of content produced by an agency.

\subsection{How do variations in WCM effect content characteristics?}

Past studies of national government Web sites have suggested that characteristics of a bureaucracy might affect the characteristics of government information available on Web sites 
(Welch \& Wong, 2001). Results from this study illustrate how characteristics of WCM structure may affect the characteristics of Web content. First, the results show that agency staff routinely forward sensitive content to high-level managers. However, the effect of highlevel review of content is unclear. On one hand, review ensures the professionalism of the content. Further, it alerts high-level agency staff-who will ultimately be accountable for the information - to the potential publication of the content. On the other hand, review may result in toning down of controversial content, a decision not to publish certain content, or removal of previously published content. The findings from this study, combined with the news reports of the removal of content from federal agency sites - such as abortion-related content from the National Institutes of Health (Connolly, 2002), condom use content from the Centers for Disease Control Web sites (OMB Watcher, 2002), or the White House Council on Environmental Quality's edits of EPA press releases related to the health effects of the World Trade Center collapse (Environmental Protection Agency, 2003) - point to the need for further investigation of how treatment of sensitive Web content differs from that of nonsensitive content, and under what circumstances content is altered or removed.

The study results also show a good deal of variation between the number of PDF and HTML files created by different agencies and different programs within agencies. Given the potential usability issues related to PDF files, more research is needed to determine what factors affect decisions about the appropriate format for content. One hypothesis is that programs with fewer staff resources (Web author span of service, percent time devoted to Web work) will produce more PDF resources because PDF requires less formatting effort. On the other hand, certain document types may require PDF use. For example, legal documents may be posted in PDF format in order to maintain their official document-like qualities better; or some documents may need to be scanned in and posted in PDF in order to show a signature.

\subsection{How do variations in WCM effect management costs?}

This article illustrates how WCM contributes to the administrative costs of agencies. The cost of developing, publishing, and disseminating information has been an ongoing concern for public agency managers (Hernon, 1989); but little data are available that show the degree to which the explosion in Web publishing has affected agency publication costs. Results from this study contribute to the investigation of costs by documenting the types of work inherent in WCM. Study results show that review and approval of new and changing Web content require the time of both lower-level Web staff (authors) and several levels of supervisors and managers (reviewers). The development of new Web sites requires the most work because it entails review and approval by multiple levels of agency staff - in some agencies up to three or four layers of approval including the agency secretary's office.

Increasing public demands for Web-based information suggests that costs associated with review and approval will rise in some circumstances. Review of increasing amounts of government information will require more staff time and resources. Alternatively, lack of resources for review and approval may discourage production of new content if the 
review and approval processes become too burdensome. While adoption of software tools may reduce some inefficiencies, it will not do away with the need for staff resources to review and approve new or changed content. This reinforces concerns that electronic government may not always provide expected cost savings (Moon, 2002). Programs that use Web publishing to increase the amount of information provided to the public (as opposed to replacing paper-based publications disseminated by mail) may see overall publications costs rise. While increased Web publication help an agency meet public education or information goals or increase citizen involvement with government, increased publication may increase overall information dissemination costs.

Little data are available about how Web content and WCM have affected agency budgets, position descriptions, or strategic communication goals. Further, little empirical information is available about how variation in WCM structures affects costs. Additional studies are needed to investigate the relationship between WCM and costs. For example, a historical perspective could show how agency publication expenses change over time with the advent of Web publishing. Further case study research could compare WCM cost information across different agencies. Additional studies focused on electronic publication costs would allow agencies to make better decisions about what types of WCM structures and content agencies can afford given goals and resource constraints.

\section{Limitations}

The primary purpose of this study was to develop the WCM framework. One limitation of the current manifestation of the framework is that it focuses primarily on organizational-level data. Examination of the within-case data shows a high degree of variation between programs within agencies including framework elements such as percentage of staff time devoted to the Web, annual budget, span of service for authors and publishers, formality of local approval processes, types of content that required local approval, and Web site size. The author plans a follow-up study to specifically examine program-level WCM factors and their relationship to desired outcomes such as amount of Web content available.

Another limitation of the framework is that it emphasizes the officially sanctioned or broadly recognized WCM structures. Participants reported many instances in which they deviated from the official structures. Other publications from this project highlight the fluid, dynamic aspects of WCM, illustrating how formal structures, while directing how content should be managed, are used differently in different situations (Eschenfelder, 2003).

Another limitation of the study is its dependence on the state search engine to generate data about the size of agency Web sites. This methodology likely undercounted the total amount of text content produced by agency staff. First, while the vast majority of content was published on official agency Web servers, in a few cases programs maintained Web sites with a private Web host. Web masters estimated that this was a very small amount of content. But this content, because it did not fall under the root URL of the agency, would not have been included in the search engine page counts. 
Further, the search engine-based count also did not include text content contained in database applications and active server pages. While the four agencies participating in the study did not employ active server pages, the search engine count still excluded text information available through Web accessible databases. Given this exclusion and the existence of some program information on nonagency Web servers, the PDF and HTML file counts likely underestimate the total amount of textual content produced by agency staff. The data can only represent the number of HTML and PDF files maintained on the official agency Web server.

Finally, the number of HTML and PDF files is not the only possible measure to represent the amount of textual content produced by agency staff. Other potential measures could include number of words per file or the number of bytes contained in files.

\section{Conclusion}

This article developed a framework to analyze and compare the structural elements that government agencies create to manage the work of reviewing and approving content for publication on agency Web sites. Study data were drawn from case studies of four public-facing agencies from one Midwestern state. The framework draws on concepts from institutional theories, contingency theories, and organizational design theories.

The framework provides a tool to systematically document WCM practices, compares WCM practices across different agencies, and observes changes in WCM practices over time. The framework provides an important base from which to explore the effects of different WCM practices on the content itself and costs related to publication and dissemination of information.

\section{Acknowledgements}

The author would like to thank the study participants, Louise Robbins, Chi-Shiou Lin, Alan Rubel, and the two anonymous LISR reviewers, for their helpful comments. This research was funded in part by a grant from the University of Wisconsin Alumni Research Foundation.

\section{References}

Barnes, S., \& Vidgen, R. (2003). Assessing the quality of a cross-national e-government Web Site: A case study of the forum on strategic management knowledge exchange. In R. Sprague (Ed.), Proceedings of the 36th Hawaii international conference on systems sciences, Vol. HICSS 03. Los Alamitos, CA: IEEE Computer Society.

Boiko, B. (2001). The content management bible. New York: Wiley.

Christensen, E., \& Hughes, J. (2000). Putting your agency on the Web. In G. Garson (Ed.), Handbook of public information systems (pp. 563-576). New York: Marcel Dekker. 
Connolly, C. (2002, October 22). Hill group faults HHS for ideology. Washington Post, A25.

Coursey, D., \& Killingsworth, J. (2000). Managing government Web services in Florida: Issues and lessons. In G. D. Garson (Ed.), Handbook of public information systems. (pp. 331-344). New York: Marcel Dekker.

Cresswell, A., \& Pardo, T. (2001). Implications of legal and organizational issues for urban digital government development. Government Information Quarterly, 18, 269-278.

Creswell, J. (1994). Research design: Qualitative and quantitative approaches. Thousand Oaks, CA: Sage.

Dawes, S., Pardo, T., \& DiCaterino, A. (1999). Crossing the threshold: Practical foundations for government services on the World Wide Web. Journal of the American Society for Information Science, 50, 346-353.

Demchak, C., Friis, C., \& La Porte, T. M. (2000). Webbing governance: National differences in constructing the face of public organizations. In G. Garson (Ed.), Handbook of public information systems (pp. 179-196). New York: Marcel Dekker.

Donaldson, L. (1995). American anti-management theories of organization. Cambridge, UK: Cambridge University Press.

Eisenhardt, K. (1989). Building theories from case study research. Academy of Management Review, 14, $532-550$.

Environmental Protection Agency (Office of the Inspector General). (2003, August 21). Evaluation report: EPA's response to the world trade center collapse: Challenges, successes, and areas for improvement (Report No. 2003-P-00012). Washington, DC: U.S. Environmental Protection Agency.

Eschenfelder, K. R. (2003). The importance of articulation work to agency content management: Balancing publication and control. Proceedings of the 35th annual Hawaii international conference on systems sciences (HICSS-36). New York: IEEE Computing Society.

Eschenfelder, K. R. (2004). Behind the Web site: An inside look at the production of Web-based textual government information. Government Information Quarterly (in press).

Fountain, J. E. (2001). Building the virtual state: Information technology and institutional change. Washington, DC: Brookings Institution Press.

Galbraith, J. (1974, May). Organizational design: An information processing view. Interfaces, 4(3), 28-36.

Galbraith, J. (1977). Organizational design. San Francisco, CA: Jossey-Bass.

Gartner Research, J. (2002). E-government: What are citizens really looking for? Stamford, CT: Gartner Research (COM-13-3960).

Hackos, J. (2001). Content management for dynamic Web delivery. New York: Wiley.

Hernon, P. (1989). Government publication during the Reagan years. Government Information Quarterly, 6, $395-410$.

Hernon, P., \& Relyea, H. (1995). Government publishing: Past to present. Government Information Quarterly, 12, 309-330.

Ho, A. T. K. (2002). Reinventing local governments and the E-Government Initiative. Public Administration Review, 62, 434-444.

Jupiter Research. (2003). The content management challenge (Research Report \# 061920031). Darien, CT: Jupiter Research.

Larsen, E., \& Rainie, L. (2002). The rise of the e-citizen: How people use government agencies' Web sites. Washington, DC: Pew Internet and the American Life Project.

Layne, K., \& Lee, J. (2001). Developing a fully functional e-government: A four stage model. Government Information Quarterly, 18, 122-136.

Miles, M. B., \& Huberman, M. A. (1994). Qualitative data analysis. Beverly Hills, CA: Sage.

Mintzberg, H. (1979). The structuring of organizations. Upper Saddle River, NJ: Prentice-Hall.

Moon, M. (2002). The evolution of e-government among municipalities: Rhetoric or reality? Public Administration Review, 62, 424-433.

Moon, M. J. (2003). Can IT help government to restore public trust? Declining public trust and potential prospects of it in the public sector. In R. Sprague (Ed.), Proceedings of the 36th Hawaii International Conference on Systems Sciences, (HICSS 03, Los Alamitos, CA: IEEE Computer Society.

Nakano, R. (2002). Web content management: A collaborative approach. Boston, MA: Addison-Wesley. 
Oliver, C. (1991). Strategic responses to institutional processes. Academy of Management Review, 16(1), $145-179$.

OMB Watcher. (2002, October 28). Ideology trumps science at HHS, letter charges. OMB Watcher. Washington, DC: OMB Watch, Available: http://www.ombwatch.org. Accessed September 19, 2003.

Orlikowski, W. (2000, July). Using technology and constituting structures: A practice lens for studying technology in organizations. Organization Science, 11, 404-428.

Perrow, C. (1967). A framework for the comparative analysis of organizations. American Sociological Review, 194-208.

Pugh, D., Hickson, D., Hinings, C., \& Turner, C. (1969). The context of organizational structures. Administrative Science Quarterly, 14(1), 91-114.

Rainey, H. G. (2003). Understanding and managing public organizations (3rd ed.). San Francisco, CA: Jossey-Bass.

Scott, W. R. (2001). Institutions and organizations. Thousand Oaks, CA: Sage.

Sprehe, J. T. (1999). Government information: From inaccessibility to your desktop and back again. Journal of the American Society for Information Science, 50, 340-345.

Strauss, A., \& Corbin, J. (1998). Basics of qualitative research. Thousand Oaks, CA: Sage.

Swanson, E. (1976). The dimension of maintenance. IEEE society second international conference on software engineering (pp. 313-326). Los Alamitos, CA: IEEE Computer Society.

Truex, D., Baskerville, R., \& Klein, H. (1999, August). Growing systems in emergent organizations. Communications of the ACM, 42(8), 117-123.

Vaughan, D. (1992). Theory elaboration: The heuristics of case analysis. In C. Ragin, \& H. Becker (Eds.), What is a case? (pp. 173-202). Cambridge, UK: Cambridge University Press.

Welch, E., \& Wong, W. (2001). Global information technology pressure and government accountability: The mediating effect of domestic context on Website openness. Journal of Public Administration Research and Theory, 11, 509-538.

West, D. (2002). State and federal e-government in the United States, 2002. Providence, RI: Center for Public Policy, Brown University.

Yin, R. (2003). Case study research: Design and methods. Newbury Park, CA: Sage.

Zucker, L. (1987). Institutional theories of organization. Annual Review of Sociology, 13, 443-464. 